International Scientific Organization

http://iscientific.org/

Chemistry International

www.bosaljournals.com/chemint/

\title{
Micelle-mediated extraction of cobalt and its spectrophotometric determination in rocks, soils, sediments and sea-bed polymetallic nodules
}

\author{
Raghbendra Thakur ${ }^{1}$, Pranab Kumar Tarafder ${ }^{1, *}$ and Raj Ranjan Jha²
}

\begin{abstract}
${ }^{1}$ Chemical Laboratory, Atomic Minerals Directorate for Exploration \& Research, Department of Atomic Energy, Khasmahal, Jamshedpur, P.0.-Tatanagar-831002, India

2Department of Chemistry, Ranchi University, Ranchi (Jharkhand), India

*Corresponding author's E. mail: pktarafder1954@gmail.com
\end{abstract}

A R T I C L E I N F O

\section{Article type:}

Research article

Article history:

Received August 2018

Accepted October 2018

January 2019 Issue

Keywords:

Cobalt

Cetyltrimethylammonium bromide

Extraction

Spectrophotometry

Rock

Thiocyanate
A B S T R A C T

The surfactant sensitized bottle-green complex (1:2:1) formed of cobaltthiocyanate-cetyltrimethylammonium bromide is suitably extracted into an organic solvent, ethylacetate, at a $\mathrm{pH}$ range, 6-8 and the absorption measurements were carried out at $630 \mathrm{~nm}\left(\lambda_{\max }\right)$. The Beer's law is obeyed in the range from 0.05 to $10 \mu \mathrm{g}$ per $\mathrm{mL}$. The molar absorptivity and Sandell's sensitivity of the present system were found to be $2.2 \times 10^{3} \mathrm{~L}_{\mathrm{mol}} \mathrm{m}^{-1} \mathrm{~cm}^{-1}$ and $0.026 \mu \mathrm{g} \mathrm{cm}{ }^{-2}$, respectively. No other element forms complex of similar colour with thiocyanate at this $\mathrm{pH}$ range. The method was applied to a number of samples like rock, soil, sediment, polymetallic nodules etc., as well as Certified Reference Materials and the values were found highly satisfactory. The interference of $\mathrm{Fe}^{3+}$ which formed a reddish complex at acidic $\mathrm{pH}(<7)$ was eliminated when the complex was extracted at $\mathrm{pH}$ 8.0. The method is highly useful for the determination of cobalt in geological samples having its concentration from $\mu \mathrm{g} / \mathrm{mL}$ to percentage level. As the method has been made highly selective for spectrophotometric determination of cobalt, it might be applied to almost all types of geological sample of diverse matrices.

(C) 2019 International Scientific Organization: All rights reserved. Capsule Summary: Determination of cobalt in micellar medium by surfactant sensitised extraction spectrophotometry was performed and the method adopted was highly efficient for the determination of cobalt in all types of geological matrices.

Cite This Article As: R. Thakur, P. K. Tarafder and R. R. Jha. Micelle-mediated extraction of cobalt and its spectrophotometric determination in rocks, soils, sediments and sea-bed polymetallic nodules. Chemistry International 5(1) (2015) 109-116.

\section{INTRODUCTION}

Cobalt is an important element because it is essentially required in the metabolic activities of plants and animals (Palit et al., 1994). Cobalt is an integral part of Vitamin, Cobalamine (Ahmed et al., 2003). Industrially it is also used in the manufacture of important alloys which are having different applications in science and technology (Banerjee et al.,1968) . Trace determination of cobalt in such diverse samples including biological ones is very important. Although cobalt is best analyzed by AAS and ICP-AES, still for certain specific applications, its spectrophotometric determinations are carried out. There are innumerable methods for the spectrophotometric determination of cobalt (Marczenko, 1976), mention may be made of $\alpha$-nitroso- $\beta$-naphthol and nitroso-R-salt. Apart from that, there are many more sensitive methods reported in literature (Gavazov et al., 2007; Trohimenko and Zaporohzets, 2013; Ahmed and Hossan, 2008; Ahmed and Uddin, 2007; Gharehbaghi et al., 
2008; Ombaka and Gichumbi, 2011; Kuliyev Kerim et al., 2016; Anusuya and Krishna Reddy, 2018; Hayashi et al., 1978; Kitson, 1950 ; Paleologos et al., 2002 ; Ramchandra Reddy et al., 2004 ), but unfortunately because of their poor selectivity, these are not, in general, used for accurate determination of the metal in diverse samples of complex matrices such as rocks, minerals, soils etc. Although the nitroso-R-salt and $\alpha$-nitroso- $\beta$-naphthol methods are still being used for the determination of cobalt in various samples, because of their less sensitivity and selectivity, they are not suitable for trace determination of cobalt in these samples.

In the course of our studies on the micelle-mediated extraction of metals like Fe (Tarafder and Thakur, 2005), Ti (Tarafder and Thakur, 2008), Mo (Das and Gambhir, 2014) etc., we have come across a facile reaction of cobalt with thiocyanate and CTAB (cetyltrimethylammonium bromide). Usually the binary Co-SCN complex in aqueous solution does not display any colour, and therefore in aqueous medium cobalt cannot be estimated spectrophotometrically using thiocyanate. However, when the binary Co-SCN complex is extracted into certain organic solvent like ethylacetate, a greenish colour is displayed in the organic solvent. The intensity of the extracted complex colour is proportional to the concentration of cobalt. The molar absorptivity of the binary Co-SCN complex being $5 \times 10^{2} \mathrm{~L}_{\mathrm{mol}}^{-1} \mathrm{~cm}^{-1}$. However, this very reaction when conducted in the presence of CTAB, the molar absorptivity $(E)$ of the ternary complex increases four-fold. Here, CTAB increases the rate of reaction of SCNwith $\mathrm{Co}^{2+}$ by way of providing micellar medium. Unlike the systems developed for metals like $\mathrm{Fe}, \mathrm{Ti}$ and $\mathrm{Mo}$, the sensitivity of Co-SCN-CTAB system is not much high $\left(\mathcal{E}=2.2 \times 10^{3} \mathrm{~L} \cdot \mathrm{mol}^{-1} \mathrm{~cm}^{-1}\right)$. In this context it is pertinent to mention here that Brown and Steinbach (1959) had in the past reported a spectrophotometric method for the determination of cobalt by extraction of Co-SCNAcetylacetone ternary system.

The sensitivity of the method was poor $(\varepsilon=0.9$ -

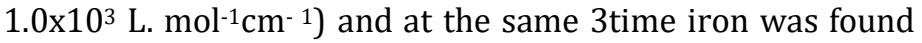
to interfere seriously. In this method, the possibility of loss of cobalt by way of its adsorption onto $\mathrm{Fe}(\mathrm{OH})_{3}$ could not be ruled out during the elimination of iron by precipitation. Similarly, in the method reported by Lorenzo Ferreira et al 1989 , the sensitivity of the method could not be improved substantially on extraction of Co-thiocyanate complex into MIBK in the presence of ephedrine $\left(\varepsilon=4.3 \times 10^{3} \mathrm{~L} . \mathrm{mol}^{-1} \mathrm{~cm}^{-1}\right)$.

Also, as pointed out in the paper, iron and $\mathrm{Cu}$ seriously interfered in the determination of cobalt. The method reported by Hayashi et al 1978 for the determination of cobalt by the extraction of Triton-X 100 sensitized Cothiocyanate complex is also not much sensitive $\left(\mathcal{E}=1.77 \times 10^{3}\right.$ L. $\mathrm{mol}^{-1} \mathrm{~cm}^{-1}$ ] [sensitization ability of Triton-X in this case was found to be poor]. Besides, like other surfactant sensitized methods for cobalt determination, this method too, is not free from serious interference of $\mathrm{Cd}, \mathrm{Fe}, \mathrm{Cu}, \mathrm{Zn}$ and $\mathrm{Ni}$. Pujar and Nagaraj (1989) reported a spectrophotometric method for the determination of cobalt in vitamin B-12 and synthetic alloys based on the extraction of Co-SCN-CTAB ternary complex into chloroform. The method claimed high sensitivity $\left(\varepsilon=2.2 \times 10^{4} \mathrm{~L}^{\mathrm{mol}} \mathrm{mol}^{-1} \mathrm{~cm}^{-1}\right.$ and $\left.\mathrm{SS}=0.008 \mu \mathrm{g} \mathrm{cm}^{-2}\right)$. It seems their claim is not correct because the reported $\varepsilon$ and Sandell's Sensitivity were not in agreement. Moreover, while re-investigating this method in our laboratory, we could not reproduce the claimed sensitivity. Besides, while applying the method to geological samples of diverse matrices, the method awfully failed due to the serious interference of iron. However, this particular system, otherwise being very specific to cobalt, is very useful for the accurate determination of the metal ion over a wide range of concentration in samples having diverse matrices like rocks, soils, sediments, minerals,sea bed polymetallic nodules, etc after eliminating iron interference.

The present report encompasses details of the systematic studies carried out on the development of a highly selective spectrophotometric method for the determination of cobalt by CTAB micelle-mediated extraction of Cothiocyanate complex into organic solvent.

\section{MATERIAL AND METHODS}

\section{Chemicals, reagents and apparatus}

A double beam spectrophotometer (Model-SPECORD 250 plus, analytikjena, Germany) equipped with $1 \mathrm{~cm}$ quartz cells was used for the absorbance measurements. The $\mathrm{pH}$ values of the reaction solutions were measured by using ELICO (LI120) $\mathrm{pH}$ meter.

All the reagents used were of Analytical reagent grade. Stock Co solution ( $1 \mathrm{mg} / \mathrm{mL}$ ): A $0.25 \mathrm{~g}$ Co as metal was weighed into a $250 \mathrm{~mL}$ beaker and was dissolved in $20 \mathrm{~mL}$ 1:1 diluted $\mathrm{HNO}_{3}$ and diluted to $250 \mathrm{~mL}$ in a volumetric flask. A working standard solution $(100 \mu \mathrm{g} / \mathrm{mL})$ was made by transferring $10 \mathrm{~mL}$ of the stock solution into a $100 \mathrm{~mL}$ volumetric flask followed by the addition of $5 \mathrm{ml}$ concentrated nitric acid and then diluting the solution to 100 $\mathrm{mL}$ with distilled water. Reagents used were; (i) potassium thiocyanate (ii), $\mathrm{HCl}$ (iii), $\mathrm{HNO}_{3}$ (iv), hydrofluoric acid (v) and cetyltrimethylammonium bromide and solvents used for liquid-liquid extraction studies were; (i) ethylacetate (ii) butylacetate (iii) benzene (iv) hexane (v) carbontetrachloride and (vi) chloroform etc.

\section{Procedure}

Dissolution of samples: The dissolution of rock and sediment samples was brought about either by $\mathrm{HF}-\mathrm{HNO}_{3}$ or by $\mathrm{NH}_{4} \mathrm{HF}_{2}-$ $\mathrm{H}_{2} \mathrm{SO}_{4}$ treatment. A $0.5 \mathrm{~g}$ sample was taken in a platinum dish, and treated with $5 \mathrm{~mL} \mathrm{HF}$. The HF treatment was repeated two times. After evaporation, the residue was treated with 5 $\mathrm{mL} \mathrm{HNO}_{3}$ till dryness. The $\mathrm{HNO}_{3}$ treatment was repeated. The solution was finally made up to $100 \mathrm{~mL}$ with distilled water in a volumetric flask by maintaining $5 \% \mathrm{HCl}$.

The soil sample (1.0 g) was weighed into a $250 \mathrm{~mL}$ Teflon high-pressure microwave acid digestion system and 
Table 1: Details of interference studies carried out for the determination of $5 \mathrm{mg} / \mathrm{L}$ cobalt

\begin{tabular}{lc}
\hline Elements/ions studied & $\begin{array}{c}\text { Tolerancelimit*, } \\
\text { (mg/L) }\end{array}$ \\
\hline $\mathrm{Na}^{+}, \mathrm{K}^{+}, \mathrm{Rb}^{+}, \mathrm{Ca}^{2+}, \mathrm{Mg}^{2+}, \mathrm{Ba}^{2+}, \mathrm{Sr}^{2+}$, & $>5000$ \\
$\mathrm{Fe}^{3+}, \mathrm{Cl}^{-}, \mathrm{Br}^{-}, \mathrm{I}^{-}, \mathrm{SO}_{4}{ }^{2-}, \mathrm{PO}_{4}{ }^{3-}$, & \\
$\mathrm{NO}_{3}{ }^{-}, \mathrm{C}_{2} \mathrm{O}_{4}{ }^{2-}, \mathrm{CH}_{3} \mathrm{COO}^{-}$ & \\
$\mathrm{Mn}^{2+}, \mathrm{Ni}^{2+}, \mathrm{Bi}^{2+}, \mathrm{Pb}^{2+}, \mathrm{Zn}^{2+}, \mathrm{Th}^{4+}, \mathrm{REEs}$ & 200 \\
$\mathrm{Mo}^{6+}, \mathrm{W}^{6+}, \mathrm{Nb}^{5+}, \mathrm{V}^{5+}, \mathrm{Ti}^{4+}, \mathrm{UO}_{2}{ }^{2+}$ & 50 \\
\hline
\end{tabular}

*less than $2 \%$ error

$10 \mathrm{~mL}$ aqua-regia was added to it. The system was operated at full power for 30 minutes in the microwave digester. The digested material was evaporated to incipient dryness. Then, $50 \mathrm{~mL}$ of $5 \%$ hydrochloric acid was added and heated close to boiling in order to leach the residue. After cooling, the residue was filtered and washed two times with a small volume of $5 \%$ hydrochloric acid. The filtrates were quantitatively collected in a $100 \mathrm{~mL}$ volumetric flask and diluted to the mark with distilled water. The sea bed polymetallic nodule sample solutions were prepared by $\mathrm{HF}$ and $\mathrm{HCl}$ treatment, and made up the volume in a $100 \mathrm{~mL}$ volumetric flask by maintaining 5\% HCl (Maxwell, 1968).

\section{Extraction and spectrophotometric measurements}

A $1 \mathrm{~mL}$ sample aliquot containing Co up to $50 \mu \mathrm{g}$ was taken in a $125 \mathrm{~mL}$ separating funnel. To it was added $5 \mathrm{~mL}$ of $10 \%$ KCNS solution, mixed well and adjusted the $\mathrm{pH}$ to around 6.0. To this solution, were added $10 \mathrm{~mL}$ of ethylacetate and $1 \mathrm{~mL}$ of $0.5 \%$ CTAB (cetyltrimethylammonium bromide). Mixed well. The mixture was shaken vigorously for three minutes and set aside for 5 minutes in order to allow for phase separation. Then, 1-2 drops of dilute (1:1) ammonia was added in order to raise the $\mathrm{pH}$ of the aqueous phase to 8.0 and again, shaken the mixture for a while. While the reddish Fe-CNS complex instantaneously vanished, the bottle green complex of cobalt (Co-SCN-CTAB) persisted in ethylacetate phase. The aqueous layer was drained out and the absorbance of the organic phase was measured at $630 \mathrm{~nm}$ $\left(\lambda_{\max }\right)$ against the reagent blank processed similarly without containing any cobalt.

\section{RESULTS AND DISCUSSION}

\section{Spectral studies}

In order to have an idea of the electronic spectra of the complex formed, absorbance of the ternary complex having increasing concentration of Co was plotted against increasing wavelength in the range, $350-800 \mathrm{~nm}$. The wavelength of maximum absorption was found at $630 \mathrm{~nm}$. Fig. 1 shows the spectra of the complex against process blank as well as that of the blank against ethylacetate.

\section{Effect of pH}

The influence of $\mathrm{pH}$ on the extraction, complex formation and colour development was studied. Under the optimized conditions of other variables like concentration of the complexing agent (potassium thiocyanate), the surfactant concentration (CTAB) and the appropriate solvent (ethylacetate), the $\mathrm{pH}$ of the reaction medium was varied over a wide range i.e., from 0 to 12 . However, it was observed that the maximum absorbance coupled with better stability of the complex formed was found to remain constant up to a $\mathrm{pH}$ of 8.5. A plot of $\mathrm{pH}$ vs. absorbance has been shown in the Fig. 2.

\section{Effect of potassium thiocyanate concentration}

In order to obtain maximum absorbance of the complex formed, the concentration of the reagent, potassiumthiocyanate was varied over a wide range, i.e., from $0.1 \%$ to $50 \%$. A $5 \mathrm{~mL}$ of $0.5 \%$ of the reagent was sufficient for obtaining maximum absorbance. Thiocyanate complexes of many metals are generally weak, and at lower concentration of CNS-, the Co-complex is unstable, but in presence of excess of the reagent (due to law of mass action) the ternary complex once formed remains stable for long. That is the reason, a higher concentration (10\% soln.) was recommended than that actually required for attaining maximum sensitivity. Fig. 3(a) shows the effect of the thiocyanate concentration on the extraction of cobalt species.

\section{Effect of surfactant concentration}

The surfactant, cetyltrimethylammonium bromide (CTAB) was found to provide a micellar medium for the reaction to take place between thiocyanate and the metal ion. Usually, the binary Co-SCN complex in aqueous solution does not display any colour, and therefore in aqueous medium, cobalt cannot be estimated spectrophotometrically using thiocyanate. However, when the binary Co-SCN complex is extracted into certain organic solvent like ethylacetate at $\mathrm{pH}$ range, 6-8, a greenish colour is displayed in the organic solvent, the intensity of colour being proportional to the concentration of cobalt. The molar absorptivity of the binary Co-SCN complex being $5 \times 10^{2} \mathrm{~L} \cdot \mathrm{mol}^{-1} \mathrm{~cm}^{-1}$.

However, this very reaction when conducted in the presence of $C T A B$, the molar absorptivity $(E)$ increased fourfold. Here, CTAB increases the rate of reaction of $\mathrm{SCN}^{-}$with $\mathrm{Co}^{2+}$ by way of providing micellar medium. The binary $\mathrm{Co}^{2+}$ ( $\mathrm{SCN}^{-}$) complex is a neutral one, hence no counter cation is required for its extraction into an organic solvent. Therefore, it is construed that $\mathrm{CTA}^{+}$of CTAB does not act as a counter cation, rather it sensitizes the colour reaction of $\mathrm{Co}^{2+}$ with KSCN by providing micellar medium only. 
Table 2: Comparison of results obtained for cobalt determination by the proposed method vis-à-vis those obtained by AAS ( $\mathrm{n}=3)$

\begin{tabular}{|c|c|c|c|c|c|}
\hline S. No & Nature of samples & Sample codes & $\begin{array}{l}\text { Co }(\mathrm{ppm}) \text { by } \\
\text { proposed method }\end{array}$ & $\begin{array}{l}\text { Co (ppm) } \\
\text { by AAS }\end{array}$ & $\begin{array}{l}\text { Literature } \\
\text { value }\end{array}$ \\
\hline 1. & Rock-Syenite & SY-3* & $15 \pm 0.4$ & 15 & 12 \\
\hline 2. & Rock-Gabbro & MRG-1* & $90 \pm 3.0$ & 91 & 86 \\
\hline 3. & $\begin{array}{l}\text { Sea-bed Polymetallic } \\
\text { nodule }\end{array}$ & $\begin{array}{l}\text { NML-Polymetallic } \\
\text { nodule* }\end{array}$ & $1370 \pm 28$ & 1360 & 1400 \\
\hline 4. & Soil & RT-912 & $29 \pm 0.8$ & 30 & - \\
\hline 5. & Soil & RT-924 & $31 \pm 0.7$ & 32 & - \\
\hline 6. & Soil & RT-936 & $42 \pm 0.8$ & 44 & - \\
\hline 7. & Soil & RT-939 & $26 \pm 0.6$ & 25 & - \\
\hline 8. & Soil & RT-940 & $<10$ & $<10$ & - \\
\hline 9. & Soil & RT-1032 & $<10$ & $<10$ & - \\
\hline 10. & Soil & RT-1033 & $12 \pm 0.3$ & 11 & - \\
\hline 11. & Sediment & RT-1034 & $19 \pm 0.5$ & 18 & - \\
\hline 12. & Sediment & RT-1035 & $29 \pm 0.7$ & 30 & - \\
\hline 13. & Sediment & RT-1036 & $11 \pm 0.2$ & $<10$ & - \\
\hline 14. & Sediment & RT-1037 & $14 \pm 0.3$ & 14 & - \\
\hline 15. & Rock & RT-1038 & $<10$ & $<10$ & - \\
\hline 16. & Rock & RT-1039 & $12 \pm 0.2$ & 11 & - \\
\hline 17. & Rock & RT-1040 & $<10$ & $<10$ & - \\
\hline 18. & Rock & RT-1041 & $21 \pm 0.5$ & 22 & - \\
\hline 19. & Rock & RT-1042 & $16 \pm 0.4$ & 14 & - \\
\hline 20. & Rock & RT-1532 & $35 \pm 0.7$ & 34 & - \\
\hline 21. & Rock & RT-1533 & $14 \pm 0.3$ & 15 & - \\
\hline
\end{tabular}

*CertifiedReference Materials

In order to see its impact on the colour formation and subsequent extraction into the organic solvent, its concentration was varied in the range, 0.1 to $2 \%(\mathrm{~m} / \mathrm{v})$. It was found that $1 \mathrm{~mL}$ of $0.5 \%$ aqueous solution of the reagent was found to be sufficient for obtaining maximum absorbance of the extracted species. However, in order to allow for reagent impurity, a $1 \mathrm{~mL}$ of $1 \%$ solution was recommended. Fig. 3(b) shows the effect of the concentration of CTAB in the colour formation and extraction of the ternary complex.

\section{Choice of solvents}

A number of polar and non-polar solvents were tried for the extraction of ternary complex of cobalt(II), with thiocyanate and CTAB. The best result, in terms of facile extraction and its better stability in the organic solvent as well as maximum absorbance of the complex formed was found with ethylacetate.

\section{Effect of equilibrium time, temperature and electrolyte on the complex formation and its extraction}

The equilibrium time for the extraction of the complex was found to be two minutes. The maximum absorbance of the complex and its stability was found to be in the temperature range, $20-40^{\circ} \mathrm{C}$. In order to verify the degree of extraction and the colour formation, various electrolytes were separately used. These electrolytes used were $\mathrm{NaCl}, \mathrm{NaNO}_{3}$, $\mathrm{NH}_{4} \mathrm{Cl}, \mathrm{Na}$ - acetate etc. It was found that the colour formation and extraction of the complex into organic solvent was independent of electrolyte addition.

\section{Beer's law, molar absorptivity, Sandell's sensitivity and precision}

The Beer's law of the system was obeyed in the range 0.05 to $10 \mathrm{ppm}$ of cobalt (Fig. 4). The regression equation of the linear calibration curve was $Y=1.09 x+0.05$ with correlation coefficient $\left(\mathrm{R}^{2}=0.98\right)$. The molar absorptivity of the complex at the $\lambda_{\max }(630 \mathrm{~nm})$ was found to be $2.2 \times 10^{3} \mathrm{~L} . \mathrm{mol}^{-1} \mathrm{~cm}^{-1}$. The Sandell's sensitivity of the method was $0.026 \mu \mathrm{g} \mathrm{cm}^{-2}$. The detection limit ( $3 \sigma$ of the blank) of the method being $0.03 \mu \mathrm{g} \mathrm{mL}^{-1}$. The precision of the method in terms of RSD was found in the range, 2 to $3 \%$.

\section{Effect of diverse ions}

Effect of foreign ions on the determination of cobalt by the prescribed procedure was studied thoroughly. Most elements which form thiocyanato complexes generally do not absorb at $630 \mathrm{~nm}$ ( $\lambda_{\max }$ for Co-SCN-CTAB complex). 


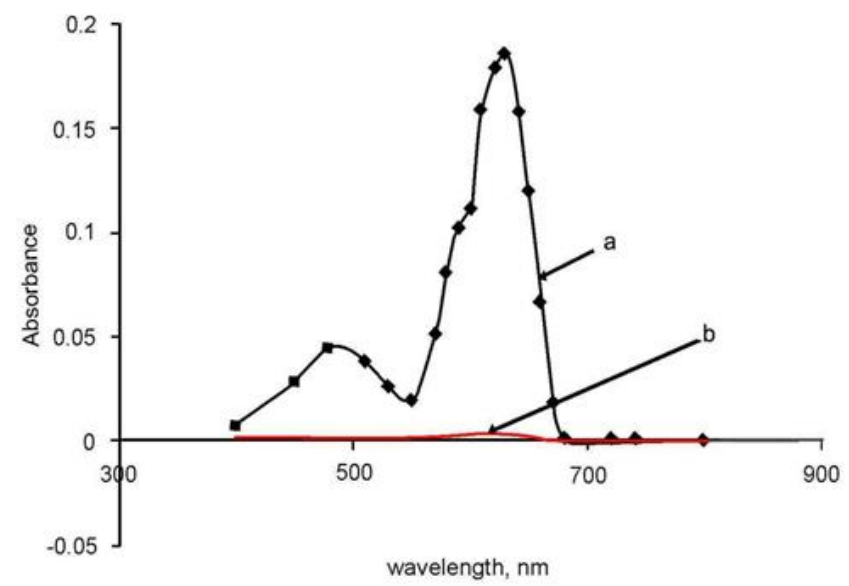

Fig. 1: Absorption spectra of (a) cobalt complex against reagent blank (b) process blank against ethylacetate

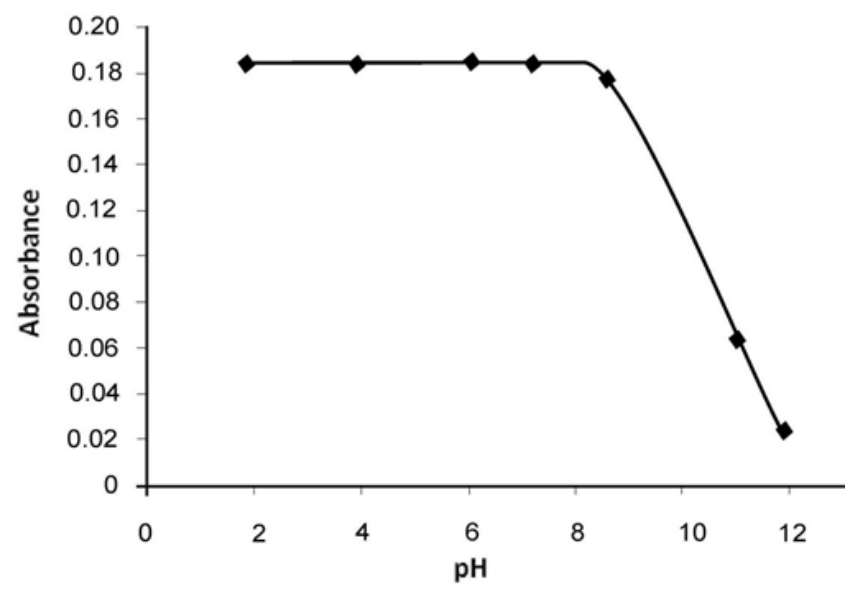

Fig. 2: Effect of $\mathrm{pH}$ on the extraction of cobalt species

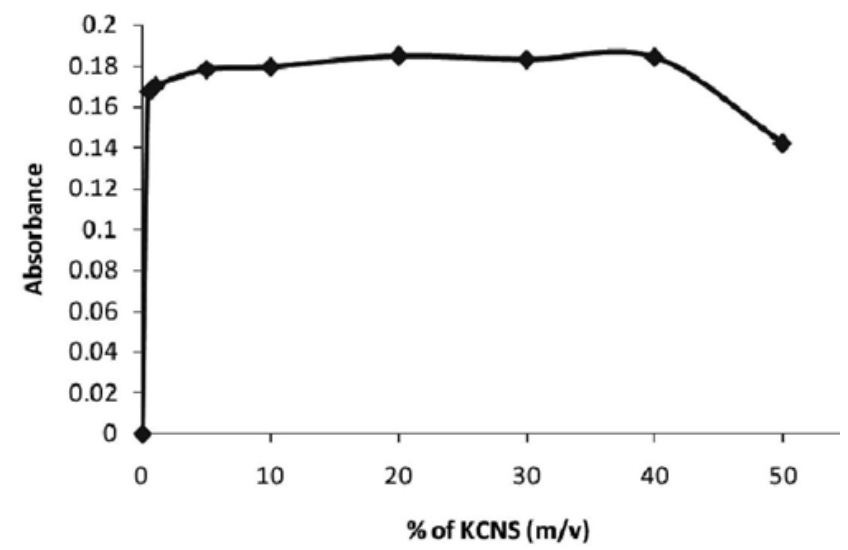

Fig. 3(A): Effect of thiocyanate concentration on the extraction of cobalt species
Hence, their interferences have not been encountered while determining cobalt. However, iron, being a major element in rocks and soil samples, forms strong thiocyanato complex in the acidic $\mathrm{pH}$ (up to a pH of 6.5), thereby interfering in the determination of cobalt, although its $\lambda_{\max }(495 \mathrm{~nm})$ is wide apart from that of Co-SCN-CTAB complex (while cobalt forms a bottle-green complex, iron forms a purple complex with thiocyanate). Interference of iron is eliminated by raising the $\mathrm{pH}$ to 8.0, where thiocyanate complex of iron is broken down (while the colour of Fe-SCN-CTAB complex readily vanishes, the colour of cobalt-thiocyanate complex remains intact). Other than iron, no interference was encountered in the determination of cobalt by this proposed technique. As such, the proposed method for cobalt-determination is highly selective because no other element forms complexes of similar colour with thiocyanate. Details of the interference studies are given in Table 1.

\section{Extraction equilibrium and tentative composition of the complex extracted}

The equilibrium studies for Co-SCN-CTAB system are given below. The mechanism by which $\mathrm{Co}^{2+}$ ion was extracted from aqueous phase into ethylacetate in the presence of the cationic surfactant, CTAB follows the reaction shown below:

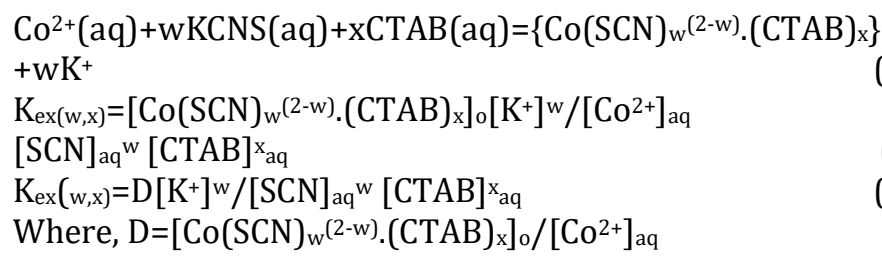

Equation (3) can be written as

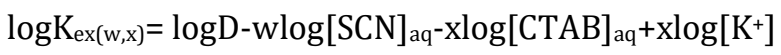

Analyzing the experimental values of the distribution ratio (D) as a function of equilibrium $\mathrm{pH}$ and extractants concentration at constant values of other parameters, allows the estimation of the number of extractant molecules associated with the extracted metal.

The composition of the Cobalt-thiocyanate-CTAB ternary complex was found out by curve-fitting method (Sillen, 1951). In order to know the number of molecules of thiocyanate participating in the formation of Cobaltthiocyanate-CTAB complex extractable in the organic solvent, different logarithmic concentrations of the reagent, thiocyanate were plotted against log D values. A slope of 1.74 close to the integer 2 was obtained (Fig. 5). This shows that two molecules of thiocyanate participated in the complex formation. Similarly, in order to know the number of molecules of CTAB participating in the formation of Cobaltthiocyanate-CTAB complex extractable in the organic solvent, different logarithmic concentrations of the reagent, CTAB were plotted against $\log \mathrm{D}$ values. A slope of 0.903 close to the integer 1 was obtained (Fig. 6). 


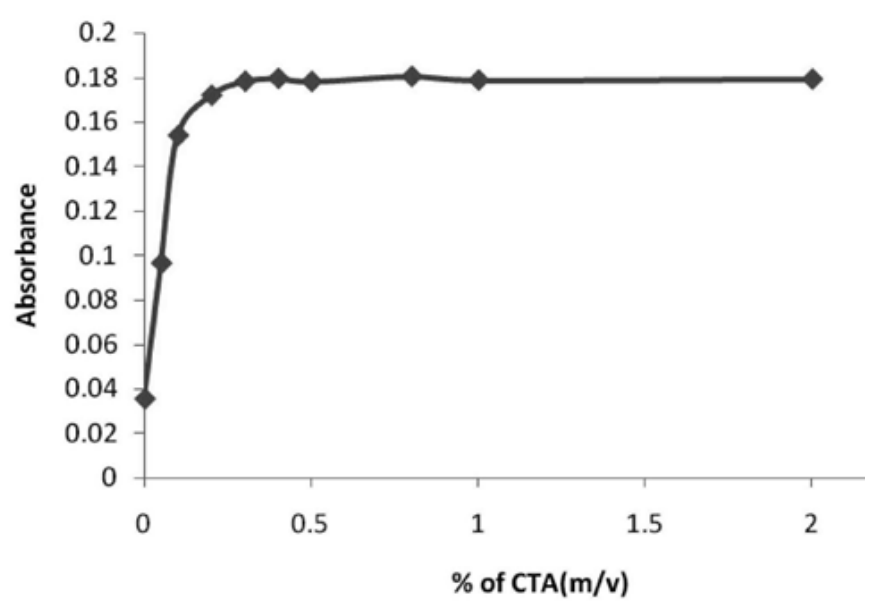

Fig. 3(B): Effect of CTAB concentration on the extraction of cobalt species

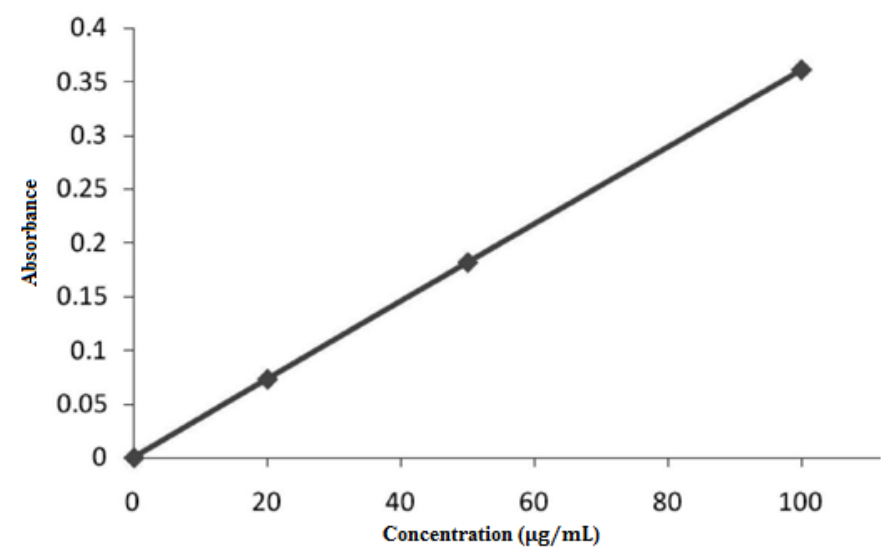

Fig. 4: Calibration graph for cobalt

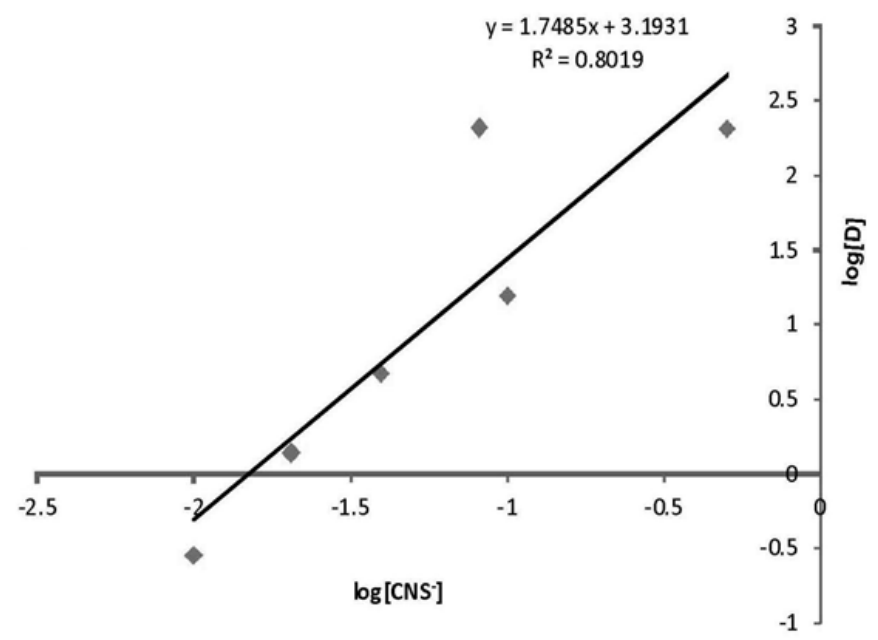

Fig. 5: Plot of log D vs. log [CNS-] (curve-fitting method)

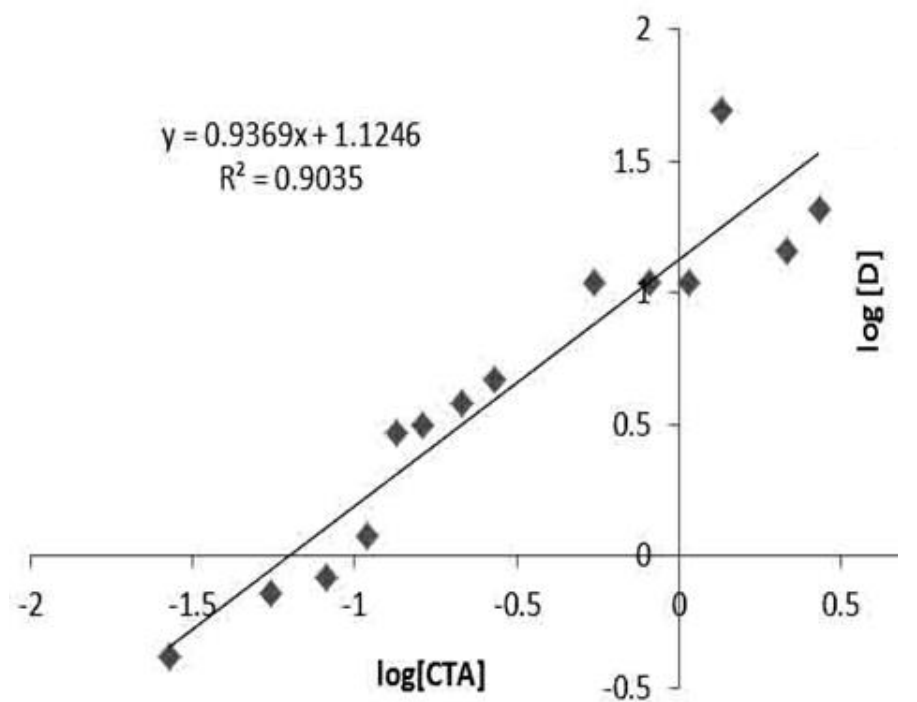

Fig. 6: Plot of $\log$ D vs. $\log$ [CTAB] (curve-fitting method)

This shows that one molecule of CTAB participated in the complex formation. Hence, the stoichiometry of the complex formed was found out to be 1:2:1. The results were further attested by Job's method of continuous variation. In this context, it is pertinent to mention here that two molecules of thiocyanate were coordinated with the metal cobalt and one mole of CTAB formed an adduct with the thiocyanate complex, which facilitated the extraction of the complex by way of providing micellar medium.

\section{Analytical application}

The extraction spectrophotometric method thus developed, is based upon the surfactant-mediated extraction of the metal. The method being highly selective has been applied to the determination of cobalt in a host of rock, soil and mineral samples including Certified Reference Material (CRMs). The results are shown in Table 2 . The results obtained were compared with those obtained from AAS (samples whose certified values are not available) as well as with certified values of CRMs. Regarding method, as is evident, the results obtained are satisfactory and this method can be used for cobalt determination (Abouhiat et al., 2017; Amin, 2014; Gurumoorthy et al., 2017; Moradi et al., 2012; Wen et al., 2013; Zou et al., 2014).

\section{CONCLUSIONS}

This is a new and highly selective method for cobalt determination in geological samples having cobalt content 10 $\mathrm{ppm}$ and above. The striking feature of the proposed method is that unlike other thiocyanate methods and their variants where iron seriously interferes (iron forms a reddish-purple, Fe-SCN complex), in the proposed method, the interference 
of iron is completely eliminated by extracting the Co-SCNCTAB complex at pH 8.0 where Fe-SCN complex gets completely broken. Thus, the method developed is highly selective for Cobalt determination in rock, soil and mineral samples.

\section{ACKNOWLEDGEMENTS}

Authors are grateful to Additional Director, Regional Director (Eastern Region) and Head Chemistry Group, AMD, for giving constant encouragement and inspiration as well as for providing necessary facilities to carry out the research work. Authors are also thankful to Director, AMD for giving permission to publish the paper.

\section{REFERENCES}

Abouhiat, Fatima Z., Henríquez, C., El Yousfi, F., Cerdà, V., 2017. Sensitive kinetic-catalytic spectrophotometric method for cobalt determination using a chip coupled to a multisyringe flow injection analysis system. Talanta $166,405-411$.

Ahmed, F., Banoo, R., Rahman, G.M.S., Khan, Md. O.F., 2003. A convenient colorimetric assay method for determination of vitamin B12 content in pharmaceutical preparations, Journal of Medical Sciences 3, 163-168.

Ahmed, M.J., Hossan K.J., 2008. A rapid spectrophotometric method for the determination of cobalt in industrial, environmental, biological, pharmaceutical and soil samples using bis(5-bromosalicylaldehyde) orthophenylenediamine (BBSOPD). Journal of the Iranian Chemical Society 5, 677-688.

Ahmed, M.J., Uddin, M.N., 2007. A simple spectrophotometric method for the determination of cobalt in industrial, environmental, biological and soil samples using bis(salicylaldehyde) orthophenylenediamine (BSOPD). Chemosphere 67, 2020-2027.

Amin, A.S., 2014. Study on the solid phase extraction and spectrophotometric determination of cobalt with 5-(2benzothiazolylazo)-8-hydroxyquinolene. Arabian Journal of Chemistry 7, 715-721.

Banerjee, B., Hauser, J., Capenos, J., 1968. Role of cobalt in the marage-type alloy matrix. Metal Science Journal 2, 76-80.

Brown, W.B., Steinbach, J.F., 1959. Sectrophotometric determination of cobalt after extraction of thiocyanate complex with acetylacetone. Analytical Chemistry 31(11), 1805-1806.

Dass, R., Kapoor, J., Gambhir, S., 2014. Spectrophotometric determination of molybdenum using surfactantmediated liquid-liquid extraction. Turkish Journal of Chemistry 38, 328-337.

Devi, V., Reddy, V.K., 2012. Spectrophotometric Determination of Iron(II) and Cobalt(II) by Direct, Derivative, and Simultaneous Methods Using 2-Hydroxy1-Naphthaldehyde-p-Hydroxybenzoichydrazone. International Journal of Analytical Chemistry 2012, 1-12.
Gavazov, K., Dimitrov, A., Lakova, V., 2007. The use of tetrazolium salts in inorganic analysis. Russian Chemical Reviews 76, 169.

Gharehbaghi, M., Shemirani, F., Baghdadi, M., 2008. Dispersive liquid-liquid microextraction and spectrophotometric determination of cobalt in water samples. International Journal of Environmental Analytical Chemistry 88, 513-523.

Gurumoorthy, G., Rani, P.J., Thirumaran, S., Ciattini, S., 2017. Cobalt(III) dithiocarbamates for anion sensing and preparation of cobalt sulfide and cobalt-iron sulfide nanoparticles: Photocatalytic degradation of dyes with as-prepared nanoparticles. Inorganica Chimica Acta 455, 132-139.

Hayashi, K., Sasaki.,Y., Tagashira, S., Itoh, K., Suzuki, M., 1978. Spectrophotometric determination of cobalt(II) with thiocyanate and surfactant. Bunseki Kagaku 27, 204-208.

Kitson, R., 1950. Simultaneous spectrophotometric determination of cobalt, copper, and iron. Analytical Chemistry 22, 664-667.

Kuliyev, K.A., Verdizadeh, N.A., Suleymanova, G.S., 2016. Spectrophotometric determination of cobalt (II) with 2, 6-dithiolphenol and its derivatives in the presence of hydrophobic amines. American Journal of Chemistry 6, 95-103.

Lorenzo Ferreira, R., Ensenat, M., Berea, M., Martinez, F.B., 1989. Extractive spectrophotometric determination of cobalt(II) as ion association complex with thiocyanate and ephedrine. Analytical Letters 22, 1819-1827.

Marczenko, Z., 1976. Spectrophotometric determination of elements . Ellis Harwood, Chichester.

Maxwell, J.A., 1968. Rock and Mineral Analysis. Wiley Interscience, New York, 97.

Moradi, R., Jameh-Bozorghi, S., Niazi, A., 2012. Extraction and Simultaneous Determination Ions Copper and Cobalt by Spectrophotometric and Chemometrics Methods. APCBEE Procedia 3, 65-69.

Ombaka, O., Gichumbi, J., 2011. Spectrophotometric determination of cobalt (ii) in low concentrations using hydroxytriazene as selective chelating agents. African Journal of Pure and Applied Chemistry 5, 494-502.

Paleologos, E.K., Prodromidis, M.I., Giokas, D.L., Pappas, A.C., Karayannis, M.I., 2002. Highly selective spectrophotometric determination of trace cobalt and development of a reagentless fiber-optic sensor. Analytica Chimica Acta 467, 205-215.

Palit, S., Sharma, A., Talukder, G., 1994. Effects of Cobalt on plants. The Botanical Review 60(2), 149-181.

Pujar, M.A., Nagaraj, P., $1989 . \quad$ Spectrophotometric determination of $\mathrm{Co}$ (II) using cetyltrimethylammonium bromide and thiocyanate. Indian Journal of Technology 27, 503-504.

Reddy, B.R., Radhika, P., Kumar, J.R., Priya, D.N., Rajgopal, K., 2004. Extractive spectrophotometric determination of cobalt (II) in synthetic and pharmaceutical samples using cyanex 923. Analytical Sciences 20, 345-349. 
Sillen, L. G., 1956. Some Graphical Methods for determining equilibrium constants II. On "curve-fitting" methods for two variable data. Acta Chemica Scandinavica 10, 186202.

Tarafder, P.K., Thakur, R. , 2008. Micelle mediated extraction of titanium and its ultra-trace determination in silicate rocks. Talanta 75, 326-331.

Tarafder, P.K., Thakur, R., 2005. Surfactant-mediated extraction of iron and its spectrophotometric determination in rocks, minerals, soils, stream sediments and water samples. Microchemical Journal 80, 39-43.

Trohimenko, A. Yu., Zaporohzets, O.A., 2013. Application of thiocyanates in chemical analysis. Metody i Ob'ekty Khimicheskogo Analiza 8, 168-185.

Wen, X., He, L., Shi, C., Deng, Q., Wang, J., Zhao, X., 2013. Application of rapid cloud point extraction method for trace cobalt analysis coupled with spectrophotometric determination. Spectrochimica Acta Part A: Molecular and Biomolecular Spectroscopy 115, 452-456.

Zou, J., Ma, J., Zhang, X., Xie, P., 2014. Rapid spectrophotometric determination of peroxymonosulfate in water with cobalt-mediated oxidation decolorization of methyl orange. Chemical Engineering Journal 253, 3439.

Visit us at: http://bosaljournals.com/chemint/

Submissions are accepted at: editorci@bosaljournals.com 